DOI: 10.17707/AgricultForest.62.1.04

\author{
Fernando SENDRA, Francisco Javier MARTÍNEZ-CORTIJO ${ }^{I}$
}

\title{
TEMPORAL EVOLUTION OF THE WATER CHEMICAL QUALITY FOR AGRICULTURAL IRRIGATION IN PEGO (ALICANTE, SPAIN)
}

\section{SUMMARY}

The purpose of this communication is to present the evolution of the chemical quality of surface water and groundwater used for irrigation of citrus and vegetables in Pego village (Southeast of Spain), during the years 2004-2014, considering the annual rainfall and the vulnerability of the area to the real risk of seawater intrusion and contamination by the application of organic fertilizers and synthetic origin. This is because irrigation is an area near the Mediterranean coast from a distance of between 2 and $11 \mathrm{~km}$.

It is a very interesting study area because it brings together two Cretaceous aquifers formed by dolomites and limestones cracked very karst landforms formed by geological materials of different chemical and solubility composition with other detrital aquifer quaternary occupying the flat and depressed area and terrain marl and clay that forms a swampy marsh (dedicated to rice and natural park) that separates it from the sandy shoal and the line of dunes along the beach of the Mediterranean Sea immediate sand.

Keywords: groundwater, seawater intrusion, electrical conductivity, chlorides, nitrates, salinity.

\section{INTRODUCTION}

The coastal plains are physiographic units of great importance for society, especially, when we study demographic and economic indicators of the municipalities. One can say that the center of gravity in many regions, as they are in Valencia, is located in the coastal plains.

These physiographic units bordering the foothills of the mountainous terrain, it is a result of the deposition of porous sediments from erosion, which extensively filled sunken tectonic structure that forms the coastline. Below, aquifers, technically called multilayer aquifers, have historically enabled the development of irrigated agriculture that has characterized the coastal regions worldwide with favourable climates, such as in the Mediterranean.

The undercurrents flowing through aquifers between descaling mixture of clays and alluvial gravel pebbles. These are the continental water recharge and discharge head to the coast this aquifer forming a characteristic circulatory system.

\footnotetext{
${ }^{1}$ Fernando Sendra, Francisco Javier Martínez-Cortijo, (corresponding authorfsendra@fis.upv.es; jamarcor@agf.upv.es:), Universitat Politècnica de València, SPAIN

Paper presented at the $6^{\text {th }}$ International Scientific Agricultural Symposium "AGROSYM 2015".

Notes: The authors declare that they have no conflicts of interest. Authorship Form signed online.
} 
These aquifers in the Spanish Mediterranean coast, such as Pego Village, enter into and bind to the valleys occupied by low course of the main surface drainage systems, which are traditional municipal orchard $s$ that have needed intensive aquifer throughout the twentieth century and so far this century.

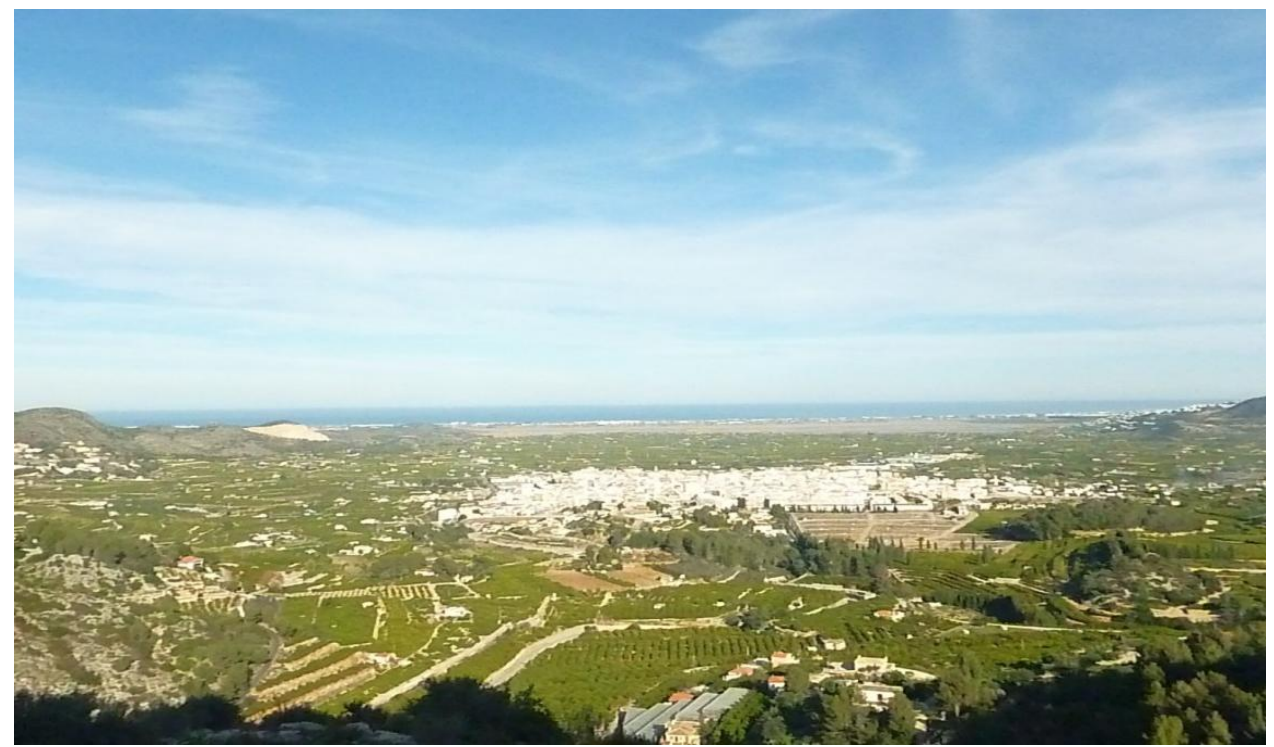

Figure 1: Pego Valley view

Pego Valley has a horseshoe shape, with the people and the sea beyond the east. To the left of the image of Figure 1 shows the output of the aquifer BenicadellAlmirall-Mostalla, north of the valley; the right end, the aquifer Alfaro-MigdiaSegària is observed on south valley; Limit centre at sea, the quaternary aquifer Gandia-Denia. The flat area is the agricultural area irrigated by wells both Cretaceous aquifers and the marsh seated on the Quaternary aquifer.

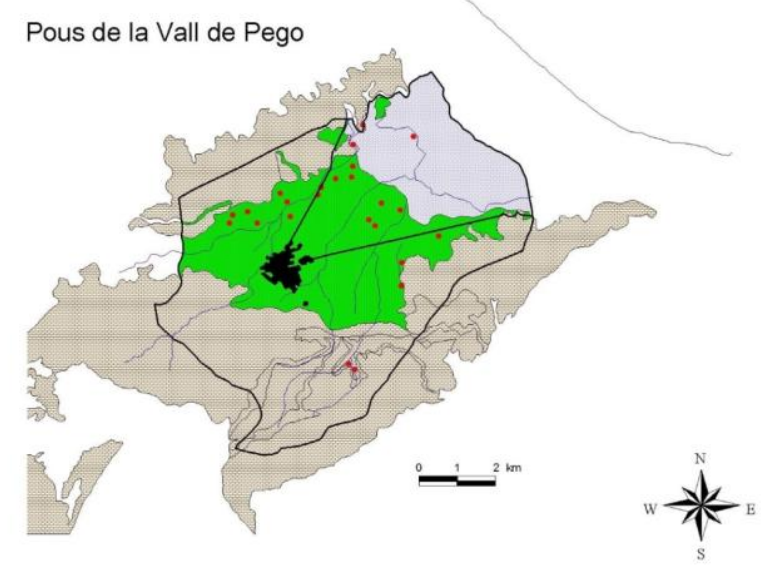

Figure 2: Pego area map 
The map (figure 2) shows schematically the indications of figure 1 photograph. We can see the position of the irrigation wells, separated quaternary aquifer sea (dark line), (green) farmland and both Cretaceous aquifer at the foot of the mountains bordering the valley.

The work is based on the chemical characterization of the evolution of these aquifers, with the analytical water wells and some surface water irrigation in the municipality of Pego. We want to show the annual evolution of the quality of water and rainfall, the distance to the waterfront and the geological substrate of irrigated land, with regard to endogenous ions and mainly exogenous.

Since 2004, we analyzed nine wells continuously supplying virtually the entire municipality and three surface water between the two Bullent (Benirrama) and Racons (Marsh) rivers delimiting the marsh in the Quaternary aquifer and an artesian well in the centre there of (Ullal Bullentó). These rivers and surface outcrops favour the recharge of coastal aquifers and seawater intrusion dimmed. This is a serious problem in all semi-arid coastal areas of the world, not just the shores of the Mediterranean.

\section{MATERIAL AND METHODS}

The study is conducted by collecting the water sample from each well and the surface in summer (July), when the water needs of crops are maximum and minimum rainfall, characteristic of the Mediterranean climate, during the intensive irrigation season.

In short, this is a field where the first activity is proceeding with the collection of samples from different waters, then make the necessary laboratory analysis of water.

For this, the protocol analysis $\mathrm{pH}$, electrical conductivity and different ions, both anions and cations, follows international standards quantization thereof. The electrical conductivity is measured with a conductivity meter, a $\mathrm{pH}$ meter for $\mathrm{pH}$, volumetry for $\mathrm{Cl}^{-}$and $\mathrm{HCO}_{3}{ }^{-}, \mathrm{NO}_{3}{ }^{-}$for colorimetry, photometry issue for $\mathrm{Na}^{+}$and $\mathrm{K}^{+}$and atomic absorption photometry for $\mathrm{Ca}^{2+}$ and $\mathrm{Mg}^{2+}$.

\section{RESULTS AND DISCUSSION}

Although fieldwork has many variables not controlled, it shows that despite the quantitative variations of the different parameters studied, usually we can observe a gradual increased electrical conductivity of all the waters of the aquifers.

Even more troubling is a slow, steady increase in the concentration of chloride ion indicator of progressive marine intrusion affecting this area, and in general the entire Mediterranean coast.

The advancement of marine intrusion is confirmed also by higher content of sodium and potassium ions. This can be seen in the following graphics (Fig. 4 and Fig. 5). 


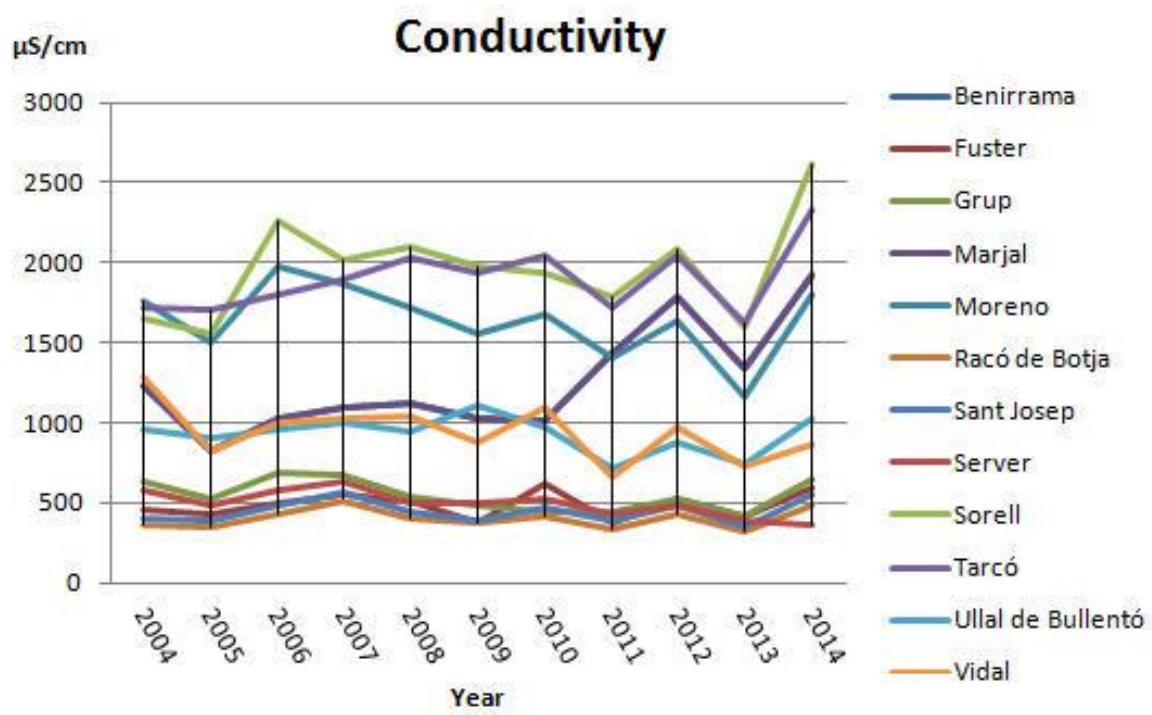

Figure 3: Conductivity evolution

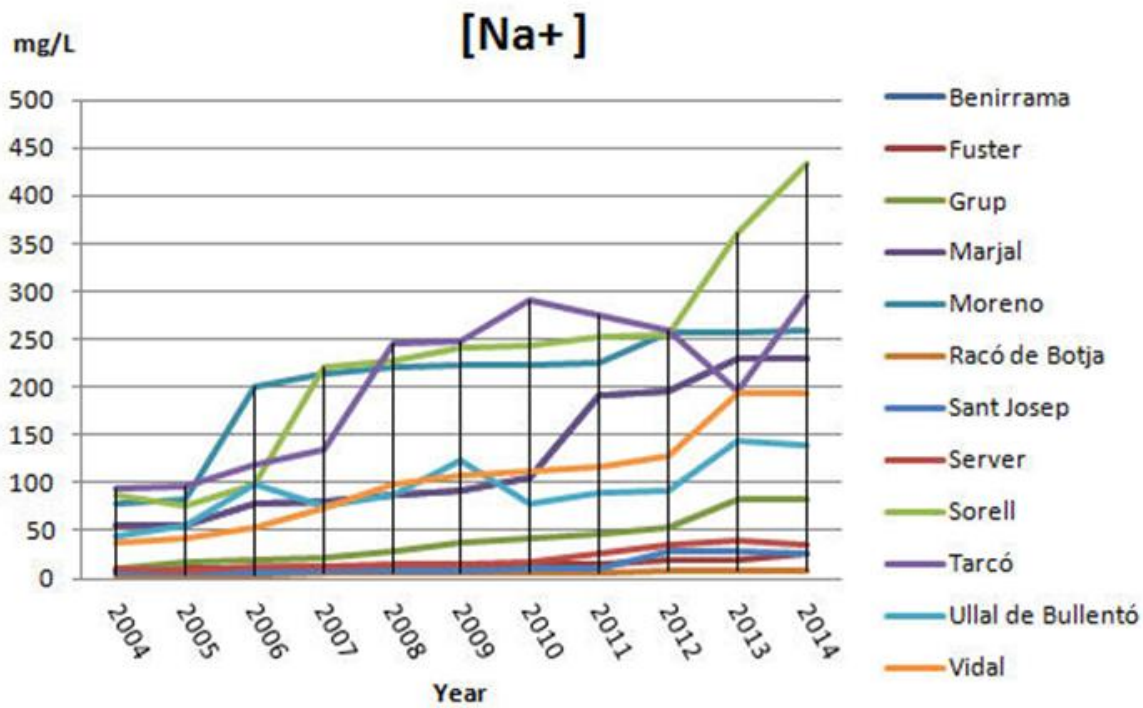

Figure 4: Sodium ion evolution

Although there may be a scenario under discussion regarding the effects of climate change, it should be noted that, according to data from the Observatory of Pego, the annual rainfall in recent years has decreased considerably and otherwise average temperature has had regular and persistent heat waves due to warm winds from the south and west. So $738.1 \mathrm{~L} / \mathrm{m}^{2}$ were recorded in 2013, with an average annual temperature of $19.8^{\circ} \mathrm{C}$, and only $350.5 \mathrm{~L} / \mathrm{m} 2$ was 
amounted to in 2014 and the average annual temperature was $21.1^{\circ} \mathrm{C}$ without so far in 2015 present a more optimistic outlook.

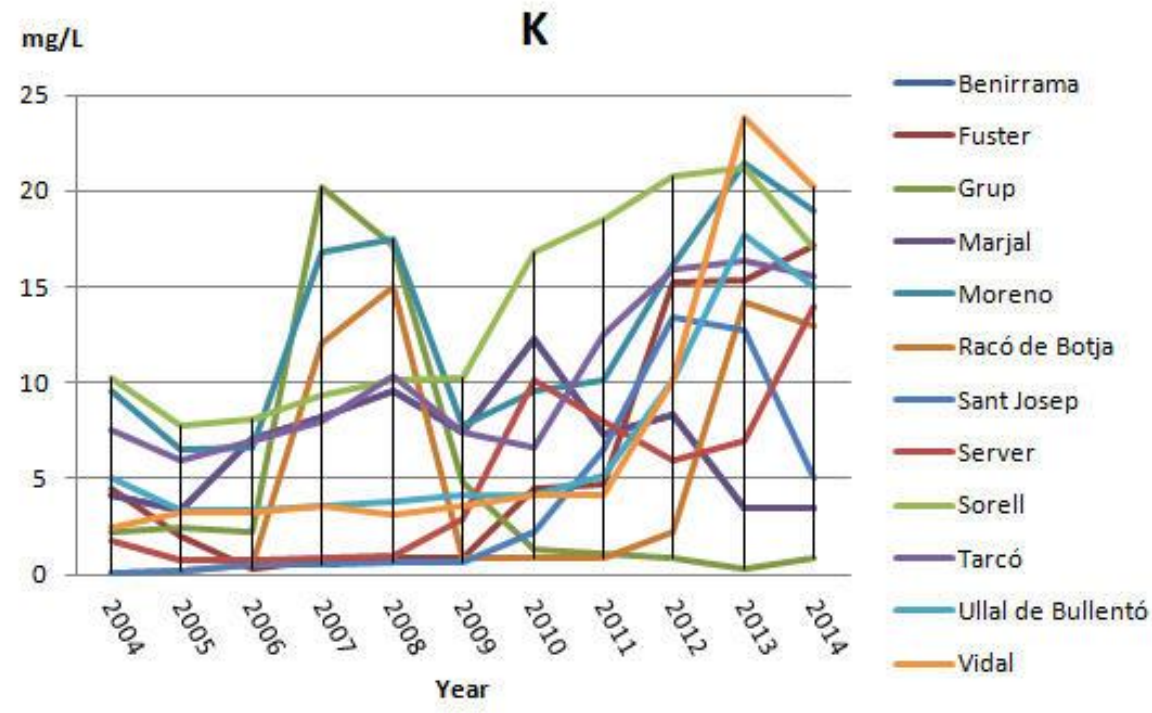

Figure 4: Potasium ion evolution

\section{CONCLUSIONS}

Improper use causes very important qualitative and quantitative changes in water quality of these aquifers, which may be unsuitable for human use and agriculture.

We have found a gradual increase in the electrical conductivity of the water with the annual monitoring carried out. While soft containment of seawater intrusion in some coastal areas is observed. Possibly, this is due to lower water pumping for irrigation to be abandoned in recent years many citrus orchards. This fact is confirmed by the diminution of the concentration of nitrates, which is directly related to the amount of nitrogen fertilizer applied.

Other observations may be due to the effect of increased drip irrigation, which implies a more smooth and continuous extraction of water by pumping and reduced surface infiltration in some areas for development of the agricultural and natural space.

\section{REFERENCES}

Pulido, A. (1979). Contribución al conocimiento de la hidrología del Prebético nororiental (Provincias de Valencia y Alicante), Servicio de Publicaciones del Ministerio de Industria y Energía, Madrid.

Sendra, F. (1995). Avaluació agroquímica dels recursos hídrics de la Marina Alta. Tesis doctoral inédita, Universidad de Alicante.

Sendra, F. \& Almela, J.M. (2006). Els pous de reg de Pego i les seues aigües, Ajuntament de Pego i Editorial Bullent, Picanya (Valencia). 